\title{
EXPERINENTAL DETERMINATION OF ELASTIC ANISOTROPY OF BEREA SANDSTONE, CHICOPEE SHALE AND CHELMSFORD GRANITE
}

\author{
Tien-when Lo, Karl B. Coyner and M. Nafi Toksöz \\ Earth Resources Laboratory \\ Department of Earth, Atmospheric, and Planetary Sciences \\ Massachusetts Institute of Technology \\ Cambridge, MA 02139
}

\begin{abstract}
We use the ultrasonic transmission method to measure $\mathrm{P}-, \mathrm{SH}-$, and SV-wave velocities for Cheimsford Granite, Chicopee Shale, and Berea Sandstone in different directions up to 1000 bars confining pressure. The velocity measurements indicate that these three rocks are elastically anisotropic. The stiffness constants, dynamic Young's moduli, dynamic Poisson's ratios, and dynamic bulk moduli of these three rocks were also calculated. These elastic constants, together with velocity measurements, suggest that: (1) Elastic anisotropy is due to the combined effects of pores/cracks and mineral grain orientation. (2) Elastic anisotropy decreases with increasing confining pressure. The residual anisotropy at higher confining pressure is due to mineral grain orientation.
\end{abstract}

\section{INTRODUCTION}

Most geologic materiais, owing to their possession of foliations (such as bedding) and/or lineations (such as preferred orientation of the long axes of mineral grains), are elastically anisotropic. Instead of two elastic constants in isotropic materials, five, nine, or even more slastic constants are required to describe the elastic properties of these materials. The determination of these elastic constants is essential if we want to properly describe the behavior of elastic waves in these materials. Many papers have been devoted to the experimental aspects of elastic anisotropy of geologic materials (Podio-Lucioni, 1968; King, 1969; Todd et al., 1973; Gregory, 1977; Bachman, 1983; White et al., 1983; Crampin, 1984). In this paper, our primary interest is the determination of anisotropy variation as a function of confining pressure. This paper is also an extension of similar experiments conducted by King $(1968,1969)$ where elastic properties of Bandera Sandstone, Berea Sandstone, and Boise Sandstone were measured. In our experiment, we measured the velocity anisotropy of P-, SH-, and SV-waves for Chelmsford Granite, Chicopee Shale, and Berea Sandstone at confining pressures up to 1000 bars; calculated the five independent stiffness constants, two dynamic Young's moduli, three dynamic Poisson's ratios, and one dynamic bulk modulus. These data reveal possible causes of velocity anisotropy for these three rocks.

Chelmsford Granite is a light gray, medium-grained quartz monzonite. In quarry terms, there are three sets of planes orthogonal to one another in this rock: "grain plane", "rift plane", and "hard-way plane". The grain plane is defined as the plane parallel to the cleavage planes of micas. The rift plane is defined as the plane paraliel to the cracks. Peng (1970) found that most of the cleavage planes of micas are perpendicular to most of the cracks. Finally, the hard-way plane is defined as the plane perpendicular to both the grain plane and the rift plane. It is also the most 
difficult plane along which this rock can be split. Chicopee Shale is a reddish-gray to reddish-brown, fine grained, arkosic micaceous shale. Its mineralogy consists of clay minerals, muscovite, quartz, arid minor amounts of feldspars and carbonate minerais. The sample used in this experiment is finely foliated with the cleavage planes of muscovite and the long axes of other constituent minerals parallel to the beciding planes. Berea Sandstone is a light brown, fine-grained, well sorted sandstone. Mineralogy consists mainiy of quartz and minor amounts of feldspars, kaolinite, and carbonate minerals. Lene and Owen (1969) made a quartz grain orientation study of Berea Sandstone which suggests that most of the quartz grains are oriented with their long axes parallel to the bedding planes. Three cylindrical samples were cut for each rock with their axes parallel, perpendicular, and 45 degree oblique to the bedding planes (Berea Sandstone and Chicopee Shale) or the rift planes (Chelmsford Granite). The samples are $5.08 \mathrm{~cm}$ long and $7.62 \mathrm{~cm}$ in diameter.

\section{VELOCITY MEASUREMENTS AND ELASTIC CONSTANTS}

The ultrasonic transmission method was used to determine velocity. Compressional and shear wave travel time across the cylindrical rock samples were measured. Typical waveforms measured in this experiment are shown in Figure 1. The length of samples was measured with a micrometer under atmospheric pressure and those measurements were corrected by linear strain measurements at higher confining pressures. Density measurements were also corrected by determining the volumetric strain from linear strain measurements. An estimate of experimental errors is listed in Appendix A.

Wave velocities measured in random perpendicular directions parallel to the bedding planes in Berea Sandstone and Chicopee Shale and parallel to the rift planes in Chelmsford Granite, showed little difference (see Table 1). However, significant difference existed between velocities measured parallel and perpendicular to these planes. Therefore, the assumption is made that all directions in the bedding planes of Berea Sandstone and Chicopee Shale and the rift planes of Chelmsford Granite are equivalent, and these rocks can be assumed to be transversely isotropic.

For transversely isotropic materials, there are five independent stiffness constants and the relationships between these constants and the velocities can be expressed by equations (1) to (5):

$$
\begin{aligned}
& C_{11}=\rho V_{P 11}^{2} \\
& C_{12}=C_{11}-2 \rho V_{S H 1}^{2} \\
& C_{33}=\rho V_{P 33}^{2}
\end{aligned}
$$




$$
C_{44}=\rho V_{S 3}^{2}
$$

$$
C_{13}=-C_{44}+\sqrt{4 \rho^{2} V_{P 45}^{4}-2 \rho V_{P 45}^{2}\left(C_{11}+C_{33}+2 C_{44}\right)+\left(C_{11}+C_{44}\right)\left(C_{33}+C_{44}\right)}
$$

$C_{11}, C_{12}, C_{13}, C_{33}, C_{44}$ are stiffness constants, $\rho$ is the density of the rock sample, and $V_{P 11}, V_{P 45}, V_{P 33}, V_{S H 1}, V_{S 3}$ are $\mathrm{P}-$ and $\mathrm{S}$-wave velocities in different directions as shown in Figure 2. In this experiment, although nine velocities (see Figure 2) were measured, only six were used to calculate the stiffness constants:

$V_{P 11}$ was used to determine $C_{11}$ by equation (1).

$V_{S H 1}$ was used to determine $C_{12}$ by equation (2.).

$V_{P 33}$ was used to determine $C_{33}$ by equation (3). (4).

The average of $V_{S 3 a}$ and $V_{S 36}\left(V_{S 3}\right)$ was used to determine $C_{44}$ by equation

$V_{P 45}$ was used to determine $C_{13}$ by equation (5).

$V_{S V 1}, V_{S H 45}$, and $V_{S V 45}$ were not used in elastic constants determination. They were used to check the predicted velocity anisotropy relationships as from equations (13) to (19).

From $C_{11}, C_{12}, C_{13}, C_{33}, C_{44}$, two dynamic Young's moduli and three dynamic Poisson's ratios can be determined by formulae given by King $(1968,1969)$. Let $D$ be the determinant of stiffness constants:

$$
D=\left[\begin{array}{lll}
C_{11} & C_{12} & C_{13} \\
C_{12} & C_{11} & C_{13} \\
C_{13} & C_{13} & C_{33}
\end{array}\right]
$$

then, 


$$
\begin{aligned}
& E_{v}=\frac{D}{C_{11}^{2}-C_{12}^{2}} \\
& E_{h}=\frac{D}{C_{11} C_{33}-C_{13}^{2}} \\
& \nu_{1}=\frac{C_{12} C_{33}-C_{13}^{2}}{C_{11} C_{33}-C_{13}^{2}} \\
& \nu_{2}=\frac{C_{13}\left(C_{11}-C_{12}\right)}{C_{11} C_{33}-C_{13}^{2}} \\
& K=\frac{C_{33}\left(C_{11}+C_{12}\right)-2 C_{13}^{2}}{C_{11}+2 C_{33}+C_{12}-4 C_{13}} \\
& \nu_{3}=\frac{C_{13}}{C_{11}+C_{12}} \\
& =
\end{aligned}
$$

where

$E_{v}=$ Dynamic Young's modulus perpendicular to the plane of isotropy.

$E_{h}=$ Dynamic Young's modulus parallel to the plane of isotropy.

$\nu_{1}=$ Dynamic Poisson's ratio, with the effect of the strain in a direction perpendicular to the axis of symmetry on the strain at a right angle to it in the same plane.

$\nu_{2}=$ Dynamic Poisson's ratio, with the effect of the strain in any direction perpendicular to the axis of symmetry on the strain parallel to the axis of symmetry.

$\nu_{3}=$ Dynamic Poisson's ratio, with the effect of the strain in a direction parallel to the axis of symmetry on the strain at a right angle to it. 
$K=$ Dynamic bulk modulus.

The whole procedure of this experiment (as shown in Figure 3 ) was controlled by an HP1000 computer, an HP3497A data acquisition/control unit, and an HP1980B oscilloscope. Two stacks of PZT ceramic transducers are housed in two titanium alloy endpieces. In each stack, there are two $1 \mathrm{Mhz}, 2.5 \mathrm{~cm}$ diameter shear discs oriented 90 degrees to each other and a similar compressional disc. After we put the sample in the pressure vessel, the control unit, which took commands from the computer, would set the confining pressure at pre-specified values. Then, the control unit started an ultrasonic pulser to generate successively a P-wave pulse and two $S$-wave pulses with perpendicular particle motion directions from the transmitting transducers. These pulses from the source transducers travel through the rock sample and the titanium alloy endpieces to the receiving transducers. Received signals were displayed on the oscilloscope and automatically digitized and sent to the computer for storage and analysis. This procedure was repeated at each pre-specifjed confining pressure automatically until the last desired pressure condition was reached.

With three velocities from each sample, a total of nine velocities ( $\mathrm{P}-$, SH-, SVwaves in different directions) were measured for each rock. These velocities are tabulated in Table 1 and are plotted in Figure 4, 5, and 6. Using equations (1) to (5), five independent stiffness constants were calculated from six of these velocity measurements and are plotted in Figure 7. Using equations (6) to (12), two dynamic Young's moduti, three dynamic Poisson's ratios referring to different directions, and one dynamic bulk modulus can also be determined and are shown in Figure 8, 9, and 10 respectively.

\section{DISCUSSION}

The anisotropy in rocks is primarily due to preferred orientation of: (1) constituent minerals, which are generally anisotropic (Simmons and Wang, 1971), (2) textural-structural features such as bedding or foliation, and ( 3 ) pores and cracks. The effects due to cracks and pores should decrease with increasing confining pressure because of the closing of cracks (Waish, 1965; Toksöz et al., 1976). Thus, at high confining pressures, the effects of preferred mineral orientation and compositional stratification should become the dominant cause of anisotropy. We will refer to this as "intrinsic" anisotropy. The effects of these three causes on the anisotropy of these three rocks are shown in Table 2. From the particle motion direction as shown in Figure 2 and these three anișotropy causes, the velocity anisotropy can be predicted as:

$$
V_{P 11}>V_{P 45}>V_{P 33}
$$

$$
V_{S H 1}>V_{S V 1}
$$




$$
\begin{aligned}
& V_{S H 45}>V_{S V 45} \\
& V_{S 3 a}=V_{S 3 b} \\
& V_{S H 1}>V_{S H 45}>V_{S 3 b} \\
& V_{S V 1}>V_{S V 45} \\
& V_{S 3 a}>V_{S V 45}
\end{aligned}
$$

Velocities listed in Table 1 support these relationships. With this background, we can now look at each rock separately. A schematic diagram of the petrofabrics of these rocks is shown in Figure 11.

\section{Chelmsford Granite}

The velocities in all directions increase as a function of confining pressure (Figure 4). The rate of increase is highest at low confining pressures and decreases gradually at confining pressures greater than about 500 bars. The initial velocity increase is due primarily to the closing of the cracks. Chelmsford Granite has about 0.9 percent porosity. Cracks do not completely close until dislocations occur at grain boundaries. However, the presence of such cracks, even as small as a fraction of one percent of rock volume, decreases the bulk and shear moduli (Toksöz et al., 1976).

The differences in velocities measured in different directions indicate that this rock is transversely isotropic. The most important cause of anisotropy is preferred orientation of cracks. At higher confining pressure, preferred orientation of biotite may also be the cause of anisotropy. Three dynamic Poisson's ratios referring to different directions converge to 0.22 as confining pressure increases. This convergence is consistent with the smaller velocity difference at higher confining pressures.

\section{Chicopee Shale}

The velocities increase monotonically with increasing confining pressure (Figure 5). The velocity anisotropy is controlled by the bedding planes. The behavior of P-, $\mathrm{SH}-$, and SV-wave velocities along different directions is consistent with those expected from particle motion diagrams shown in Figure. 2. The transversive isotropy holds well as can be seen from the equality of $V_{S 3 a}$ and $V_{S 3 b}$ in Table 1 . Three dynamic Poisson's ratios remain almost constant with increasing confining pressure. 
This is due to the relative unimportance of the role of cracks or pores on the elastic properties of shales.

\section{Berea Sandstone}

In Berea Sandstone, weakly preferred orientation of cracks and flat pores is the most important cause of anisotropy. SEM images of Berea Sandstone (Simmons et al., 1982) show that the thinnest cracks are between the relatively flat surfaces of the sand grains. The Berea Sandstone sample used in this experiment has a porosity of $17 \%$. Cracks close at pressures less than 500 bars. Decrease of P- and SH-wave anisotropy with confining pressure (Figure 6) can be explained by the closing of cracks and the establishment of strong grain-to-grain contact. Convergence of three dynamic Poisson's. ratios to 0.11 as confining pressure increases beyond 500 bars (Figure 9) also agree with this explanation.

The persistence of differences between SV-wave velocities ( $V_{S V 45}$ lower than $V_{S V 1}$ and $V_{S 3 a}$ ) up to 1 kilobar confining pressure suggests the presence of preferred orientation of quartz grains. Lene and Owen (1969) have found that the long axes of quartz grains are orlented nearly parallel to the bedding plane. This is consistent with the lower values of $V_{S V 45}$. The P- and S-wave velocities of Berea Sandstone measured in this experiment is about $0.1 \mathrm{~km} / \mathrm{sec}$ faster than those measured by King (1969). At higher confining pressures, the differences in S-wave velocitles in King's measurements $(1968,1969)$ are also smaller than those in this experiment. Both discrepancies can be explained either by the higher porosity of King's sample (22\%), or by the improved measuring system used in this experiment (sharper ultrasonic pulses).

\section{CONCLUSIONS}

The three rocks (Chelmsford Granite, Berea Sandstone, and Chicopee Shale) show velocity anisotropy due to contributions of varying degrees of preferred orientation of pores and cracks, bedding planes, and mineral grains. The anisotropy decreases with increasing confining pressure. This is primarily due to the closing of pores and cracks. Some anisotropy persists at 1 kilobar confining pressure, corresponding to about $4000 \mathrm{~m}$ earth depth. This residual anisotropy is due primarily to contributions of bedding planes and preferred orientation of mineral grains. All five stiffness constants, shown in Figure 7 for these three rocks, increase with increasing confining pressure. These indirectly measured stiffness constants satisfy the following theoretical bounds obtained by Postma (1955):

$$
\begin{aligned}
& C_{11}>\frac{C_{11}-C_{12}}{2}>C_{44}>0 \\
& C_{11}>C_{33}
\end{aligned}
$$


The dynamic Young's moduil (Figure 8), the dynamic Poisson's ratios (Figure 9), and the dynamic bulk modulus (Figure 10) measured in this experiment are very close to those measured by King $(1968,1969)$. The dynamic Young's moduli and dynamic bulk moduli all increase with increasing confining pressure. This can be explained by the closure of pores and cracks, and stronger grain-to-grain contacts at higher confining pressure. Besides, $E_{h}$ (dynamic Young's modulus parallel to the plane of isotropy) is always larger than $E_{y}$ (dynamic Young's modulus perpendicular to the plane of isotropy). This is consistent with the observation that the long axes of the quartz grains in Berea Sandstone, the mineral grains in Chicopee Shale, and the cracks in Chelmsford Granite, are oriented parallel to the plane of isotropy.

\section{ACKNOWLEDGEMENTS}

The authors would like to thank Professor G. Simmons, Professor K. Hodges, and V. Cormier, J. Walsh, and R. Wilkens for their suggestions and comments.

\section{REFERENCES}

Bachman, B. T., 1983, Elastic anisotropy in marine sedimentary rocks: J. Geophys. Res., 88, 539-545.

Crampin, S., 1984, An introduction to wave propagation in anisotropic media: Geophys. J. R. Astr. Soc., 76, 29-39.

Gregory, A. G., 1977, Aspects of rock physics from laboratory and log data that are important to seismic interpretation, in Payton, C.E., Editor, Seismic stratigraphy: Memoir 26, AAPG, 15-46.

King, M. S., 1968, Ultrasonic compressional and shear-wave velocities of confined rock samples, in Hughes, J., Editor: Proceedings of the 5th Canadian rock mechanics symposium, Toronto, 127-156.

King, M. S., 1969, Static and dynamic moduli of rocks under pressure, in Somerton, W.H., Editor, Rock mechanics - theory and practice : Proceedings of the 11th symposium on rock mechanics, Univ. of Calif., Berkeley, 329-351.

Lene, G.W. and Owen, D.E., 1969, Grain orientation in a Berea Sandstone channel in South Amherst, Ohio: J. Sed. Petrology, 39, 737-743.

Peng, S. D., 1970, Fracture and failure of Chelmsford Granite, Ph.D. thesis, Stanford Univ., Stanford.

Podio-Lucioni, A., 1968, Experimental determination of the dynamic elastic properties of anisotropic rock, ultrasonic method, Ph.D. thesis, Univ. of Texas, Austin.

Postma, G. W., 1955, Wave propagation in a stratified medium: Geophysics, 20,780 806.

Simmons, G. and Wang, H., 1971, Single crystal elastic constants and calculated aggregate properties: a handbook, MIT Press. 
Simmons, G., Wilkens, R., Caruso, L., Wissler, T., and Miller, F., 1982, Physical properties and microstructures of a set of sandstone, an annual report to the Schlumberger-Doll Research Center.

Todd, T., Simmons, G., and Baldridge, W. S., 1973, Acoustic double refraction in lowporosity rocks: Bull. Seismol. Soc. Am., 63, 2007-2020.

Toksöz, M. N., Cheng, C. H., and Timur, A., 1976, Velocities of seismic waves in porous rocks: Geophysics, 41, 621-645.

Walsh, J. B., 1965, The effect of cracks on the compressibility of rock: J. Geophys. Res., $70,381-389$.

White, J. E., Martineau-Nicoletis, L., and Monash, C., 1983, Measured anisotropy in Pierre Shale: Geophysical Prospecting, 31, 709-725. 


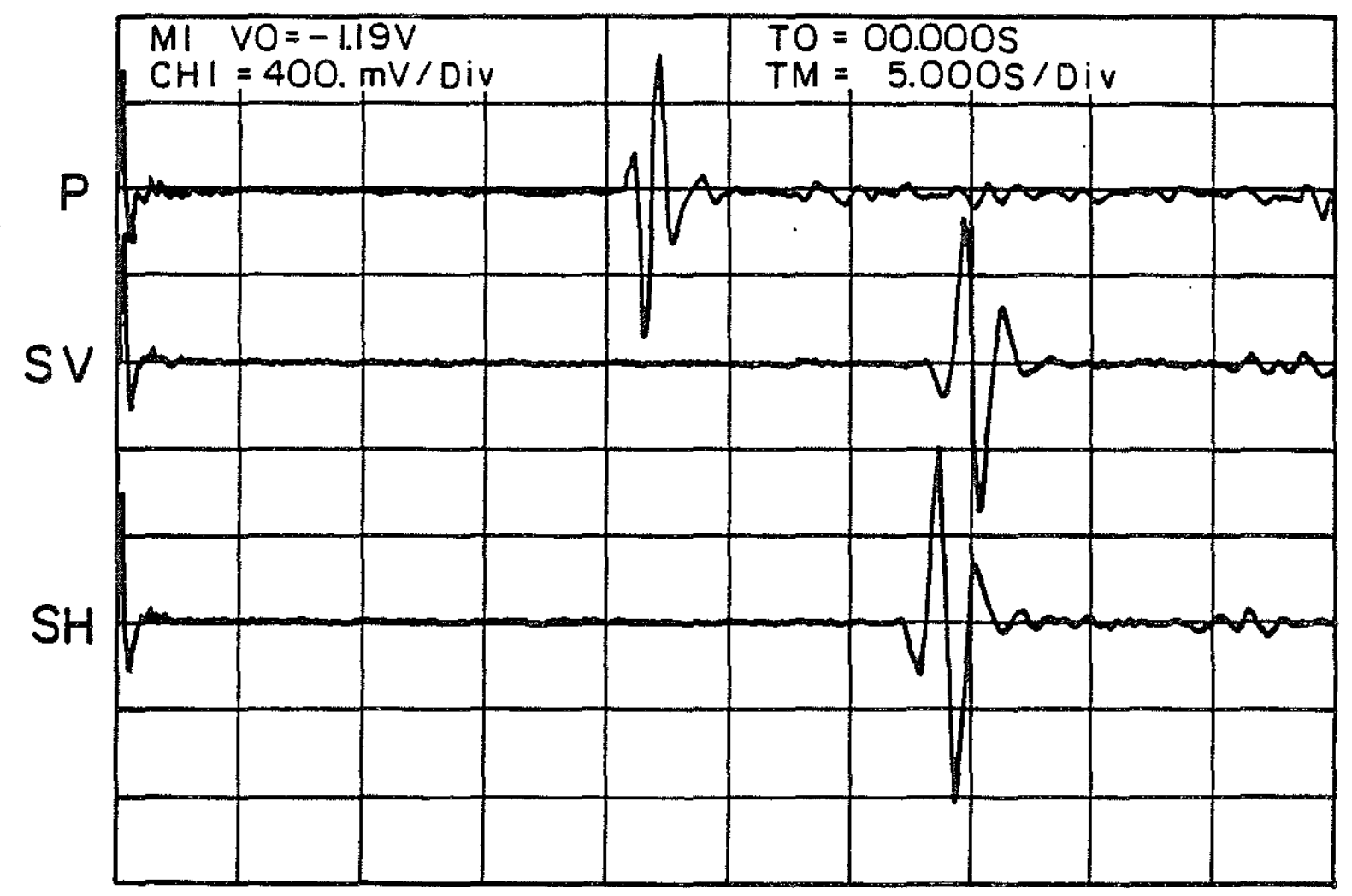

FIG. 1. Examples of ultrasonic waveforms sequentially measured through a $5.08 \mathrm{~cm}$ thick core of Chelmsford Granite at 1000 bars confining pressure. Top trace is a $\mathrm{P}$-wave, middle trace is an SV-wave, and the bottom trace is an SH-wave. Signals are attenuated by $-20 \mathrm{~dB}$. The vertical voltage scale is $400 \mathrm{mv} / \mathrm{div}$, the time scale is $5 \mu \mathrm{sec} / \mathrm{div}$. The left edge of the plot is the zero time at which the transmitting transducer is excited. Delay time introduced by the titanium endpieces is approximately $7.54 \mu \mathrm{sec}$ for the P-wave, $13.7 \mu \mathrm{sec}$ for the SV-wave, and $12.45 \mu \mathrm{sec}$ for the SH-wave. S-wave arrival times are offset in the mechanical transducer design to isolate crosstalk. 

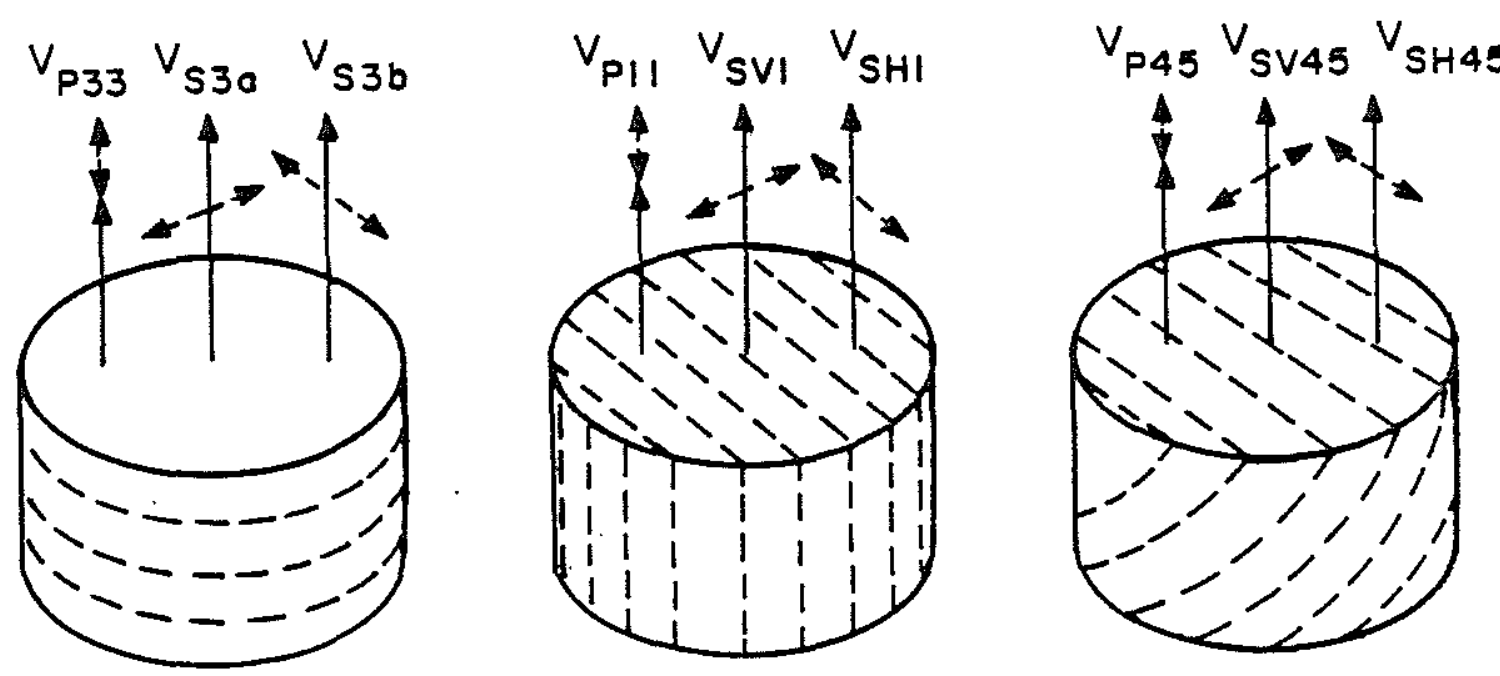

FIG. 2. Velocities measured in this experiment. Solid arrows represent directions of wave propagation; dashed arrows represent directions of particle motion, dashed lines in the sample indicate bedding planes in Berea Sandstone and Chicopee Shale and rift planes in Chelmsford Granite. 


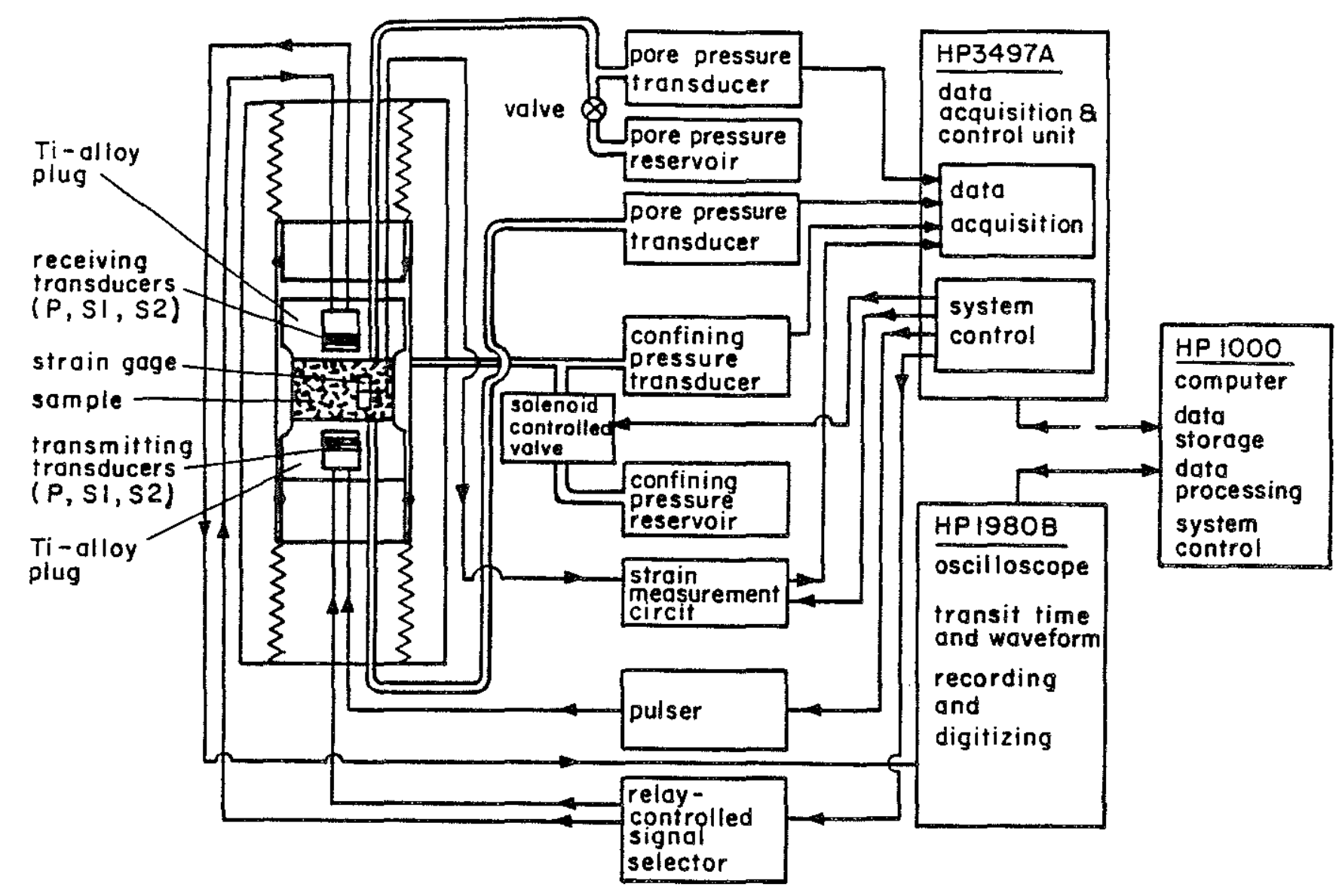

FIG. 3. Block diagram of measuring system. On the left side is the high-pressure vessel which houses the rock sample and the ultrasonic transducers. The pressure inside the pressure vessel is controlled by an HP1000 computer through a control unit (right upper side of this diagram) and a solenoid-controlled valve (in the center of this diagram). The transmitting and receiving of ultrasonic pulses from the ultrasonic transducers are controlled by the computer, the control unit, and the oscilloscope (right lower side of this diagram) through the pulser and the signal selector in the lower middle part of this diagram. 


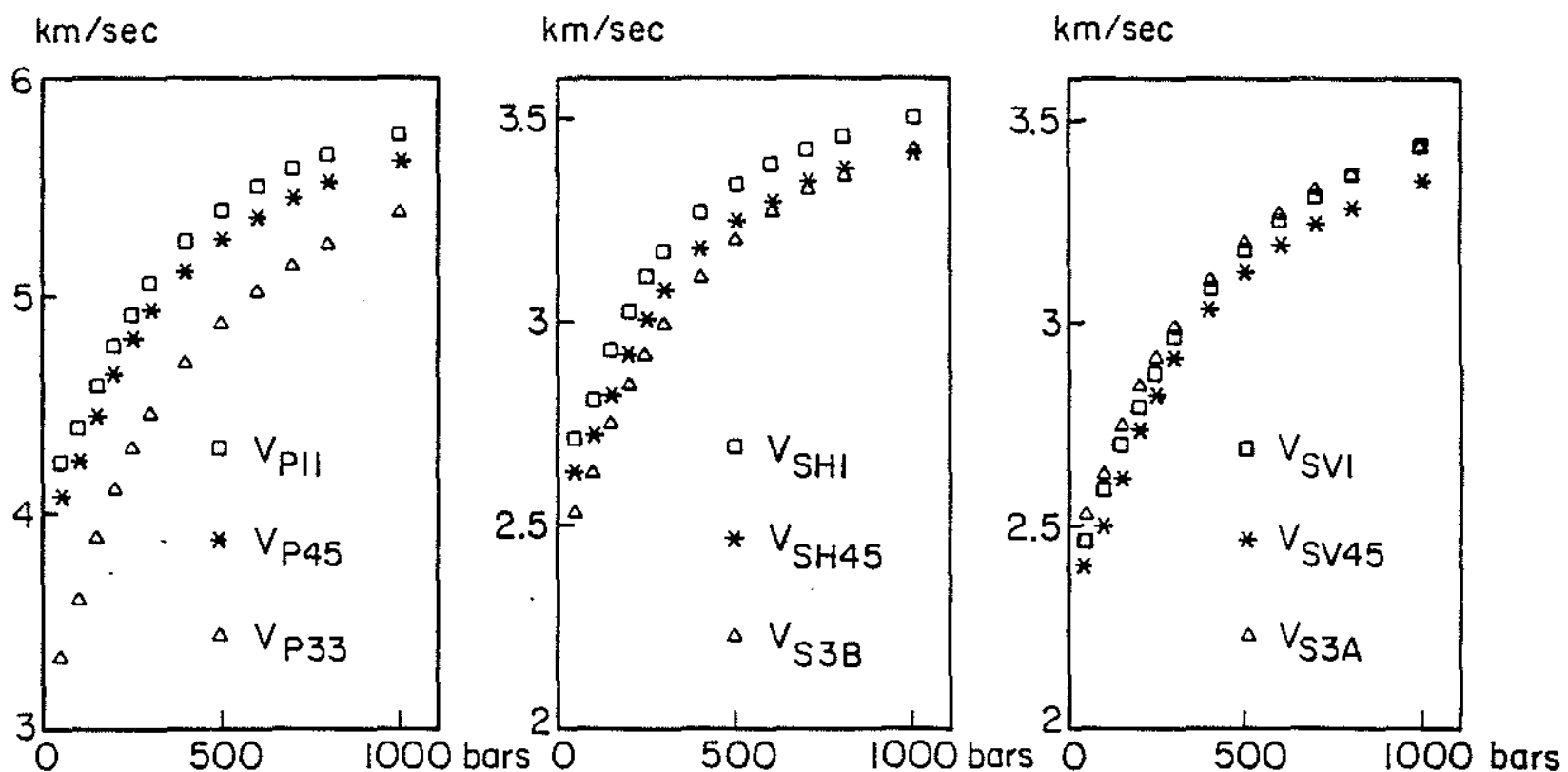

FIG. 4. P-, SH-, and SV-wave velocities in different directions for Chelmsford Granite. Subscripts indicating directions are defined in Fig. 2. 


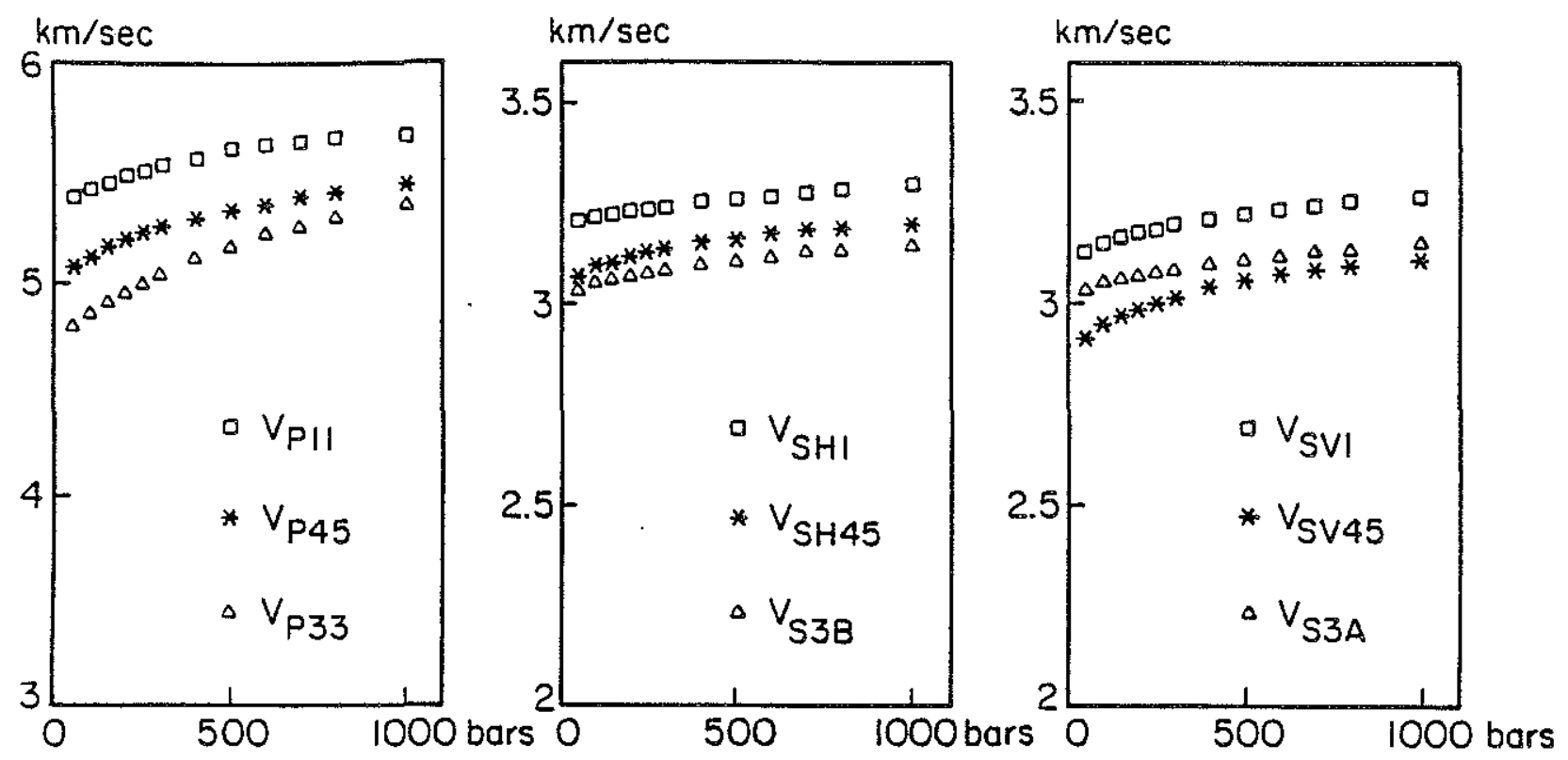

FIG. 5. P-, SH-, and SV-wave velocities in different directions for Chicopee Shale. Subscripts indicating directions are defined in Fig. 2. 


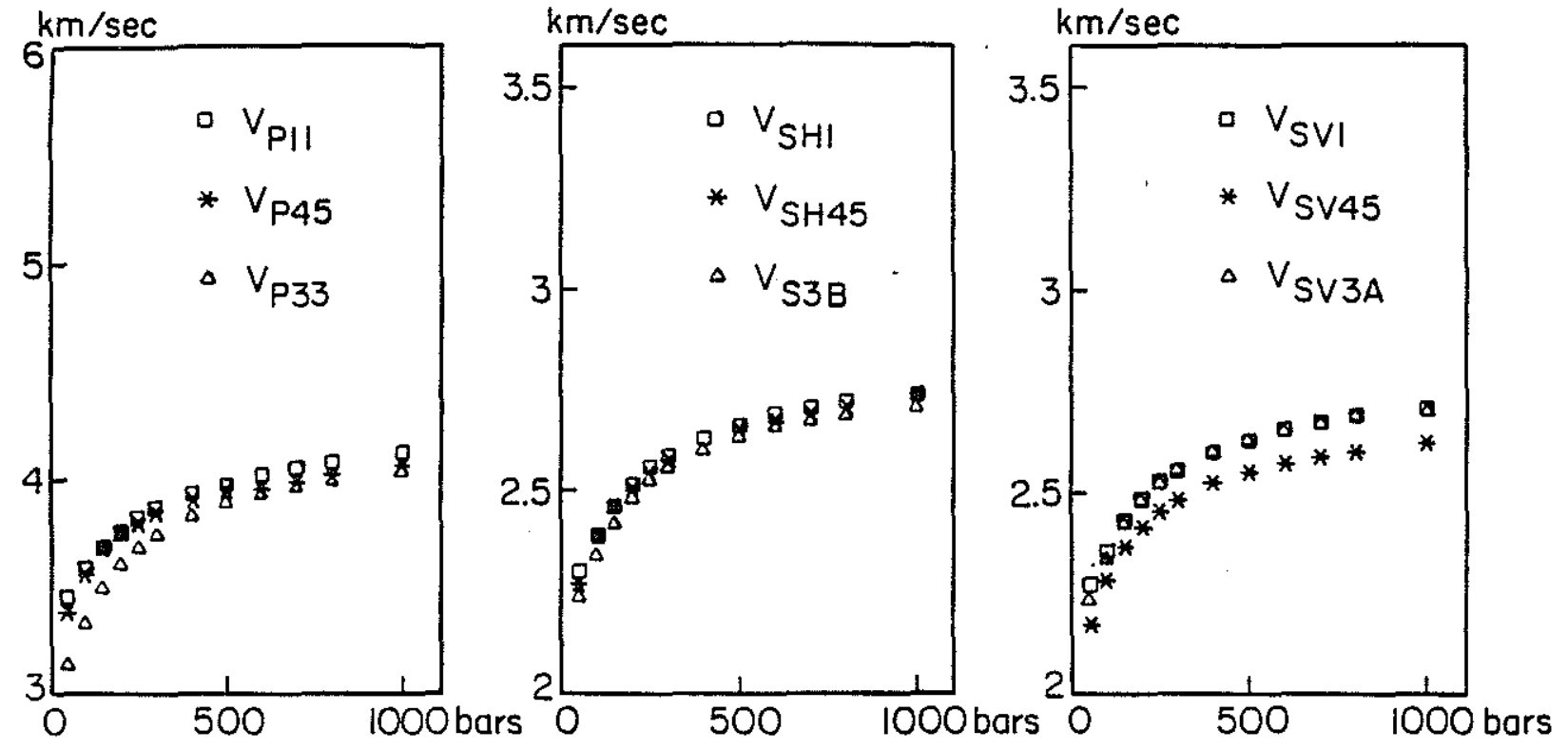

FIG. 6. P-, SH-, and SV-wave velocities in different directions for Berea Sandstone. Subscripts indicating directions are defined in Fig. 2. 


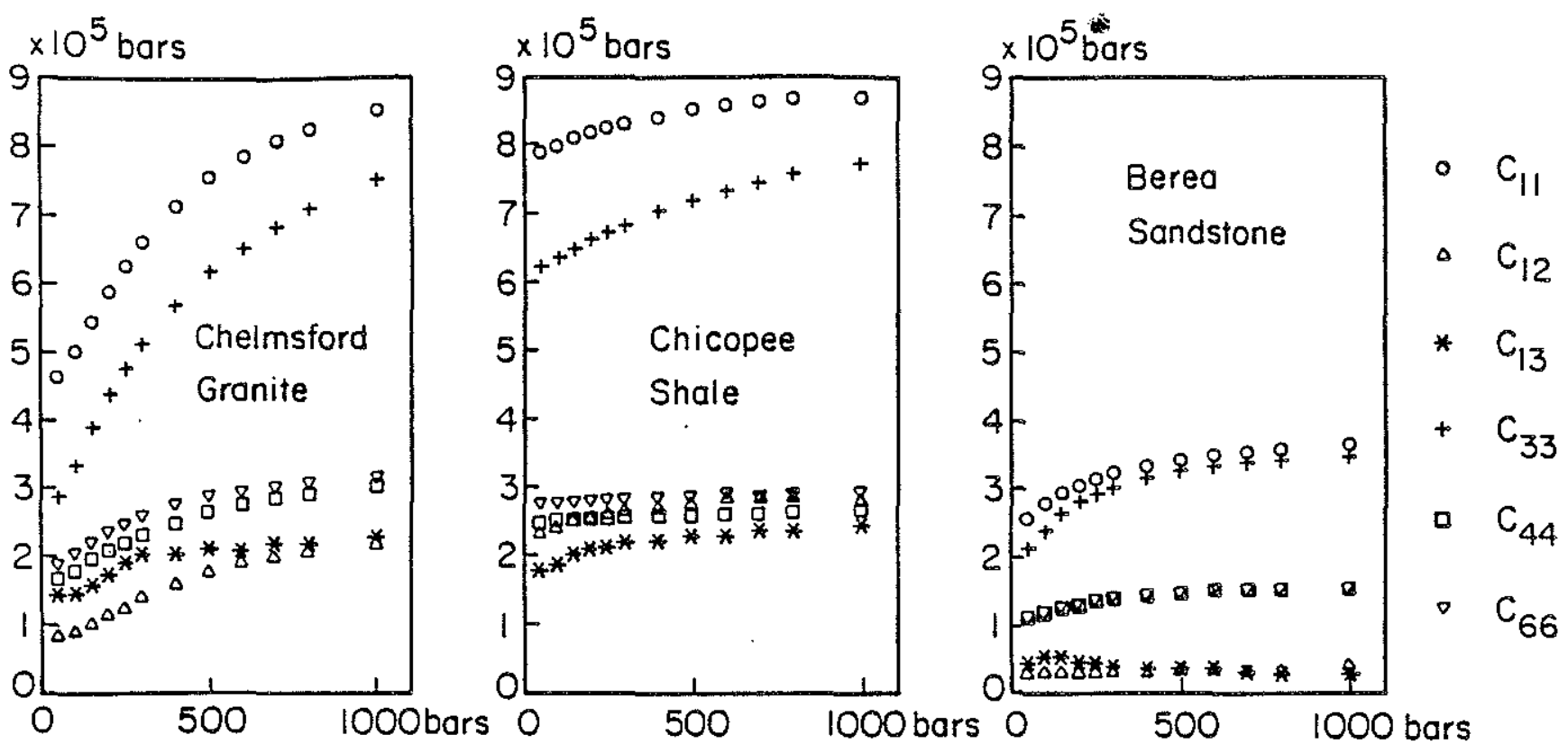

FIG. 7. Stiffness constants vs. confining pressure. $C_{i j}$ constants are defined by equations (1) to (5). 

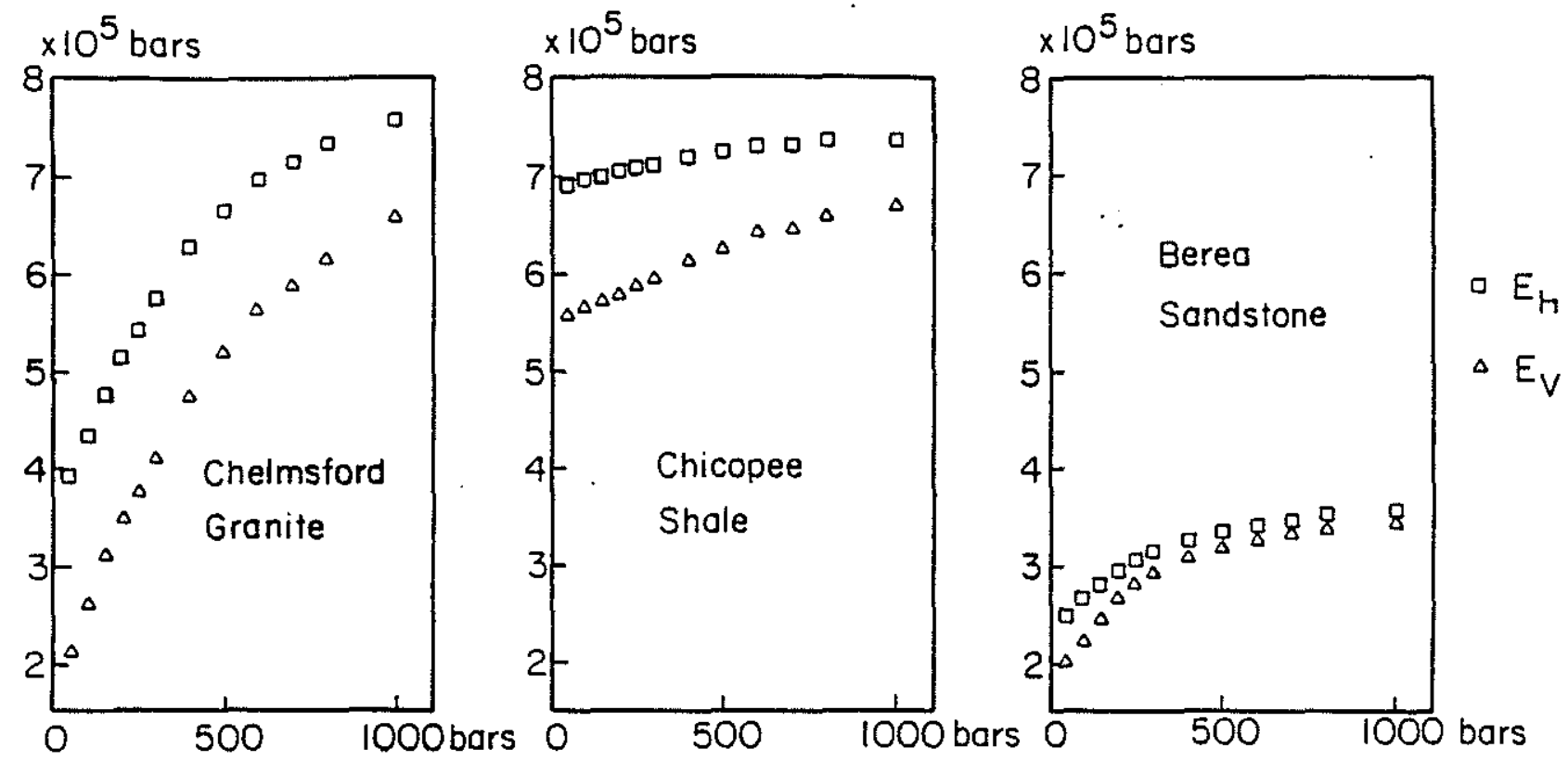

FIG. 8. Dynamic Young's moduli vs. confining pressure. $E_{v}=$ Dynamic Young's modulus perpendicular to the plane of isotropy. $E_{h}=$ Dynamic Young's modulus parallel to the plane of isotropy. 

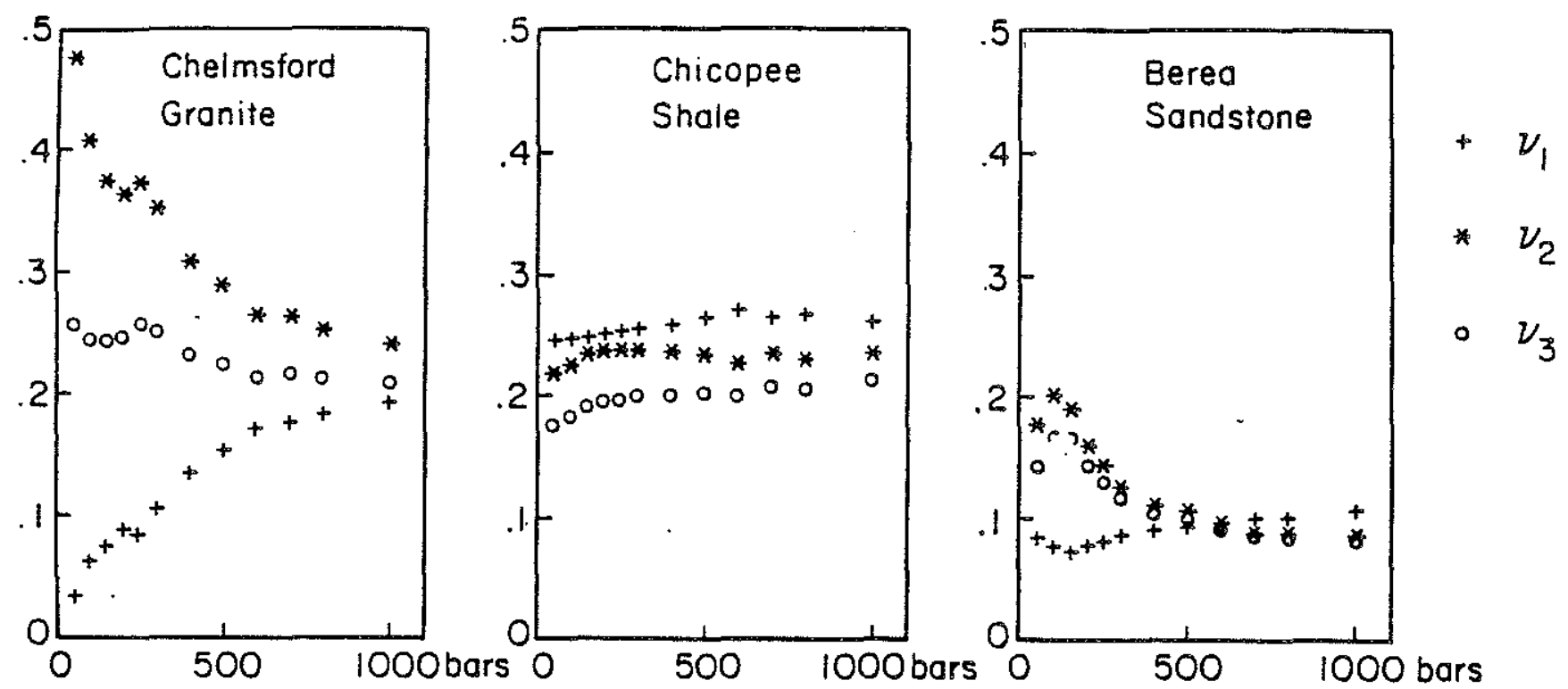

FIG. 9. Dynamic Poisson's ratios vs. confining pressure. $\nu_{1}=$ Dynamic Poisson's ratio, with the effect of the strain in a direction perpendicular to the axis of symmetry on the strain at a right angle to it in the same plane. $\nu_{2}=$ Dynamic Poisson's ratio, with the effect of the strain in any direction perpendicular to the axis of symmetry on the strain parallel to the axis of symmetry. $\nu_{3}=$ Dynamic Poisson's ratio, with the effect of the strain in a direction parallel to the axis of symmetry on the strain at a right angle to it. 


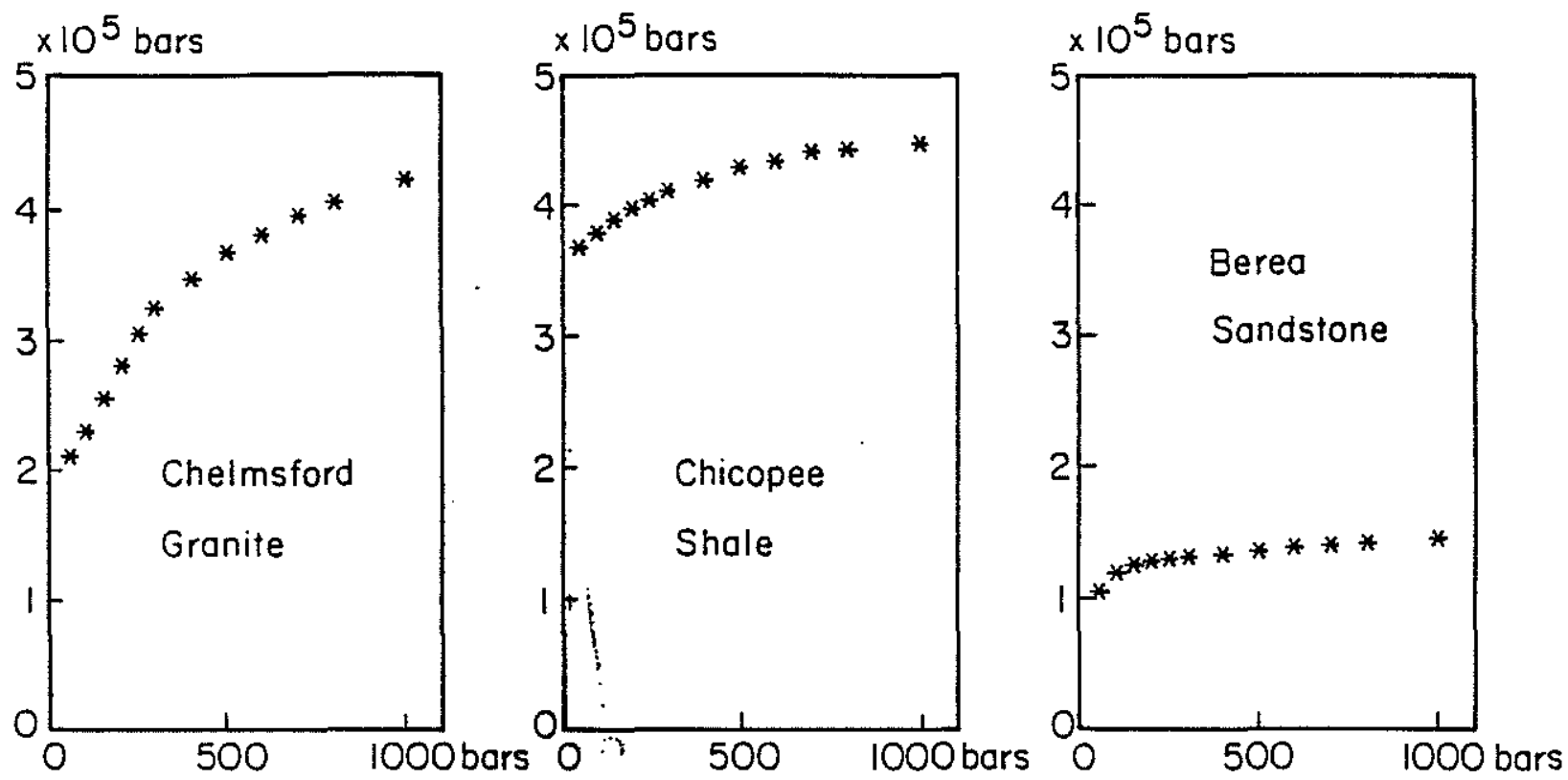

FIG. 10. Dynamic bulk modulus vs. confining pressure. 
pore space

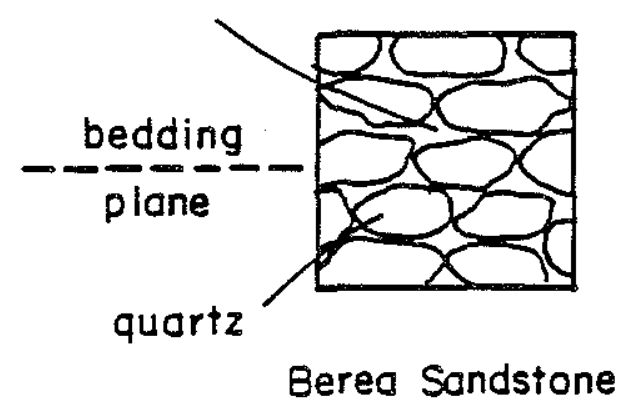

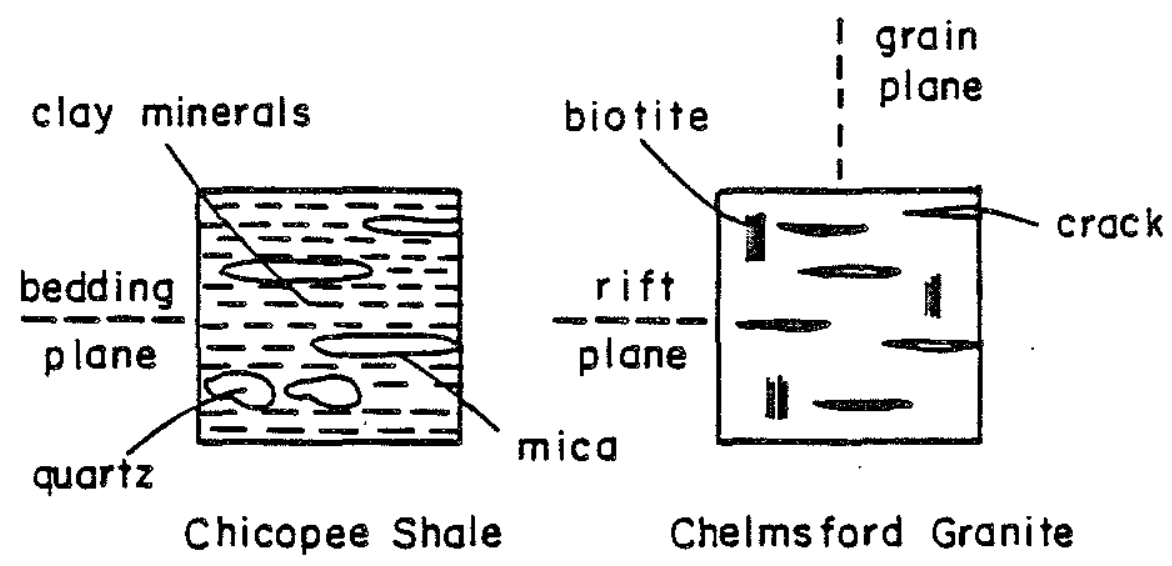

FIG. 11. Schematic diagrams showing the petrofabric characters of rock samples used in this experiment. In Berea Sandstone, most of the long axes of the quartz grains are parallel to the bedding plane. In Chicopee Shale, most of the cleavage planes of mica and the long axes of other constituent minerals are parallel to the bedding plane. In Chelmsford Granite, most of the penny-shaped cracks are parallel to the rift plane and most of the biotite cleavage planes are parallel to the grain plane. 


\begin{tabular}{|c|c|c|c|c|c|c|c|c|c|}
\hline $\begin{array}{l}\text { confintng } \\
\text { pressure } \\
\text { (bars) }\end{array}$ & $V_{P 11}$ & $v_{P 45}$ & $v_{\text {P.33 }}$ & $\mathrm{V}_{\text {SH1 }}$ & $\begin{array}{c}\mathrm{V}_{\mathrm{sVl}} \\
(\mathrm{km} / \mathrm{se}\end{array}$ & $V_{\text {SH45 }}$ & $v_{\text {SV45 }}$ & $v_{S 3 a}$ & $V_{S 3 b}$ \\
\hline \multicolumn{10}{|c|}{ Chelmsford Granite } \\
\hline $\begin{array}{r}50 . \\
100 . \\
150 . \\
200 \\
250 \\
300 \\
400 \\
500 \\
600 \\
700 \\
800 \\
1000\end{array}$ & $\begin{array}{l}4.23 \\
4.40 \\
4.59 \\
4.77 \\
4.92 \\
5.06 \\
5.25 \\
5.40 \\
5.51 \\
5.59 \\
5.65 \\
5.74\end{array}$ & $\begin{array}{l}4.08 \\
4.24 \\
4.45 \\
4.64 \\
4.80 \\
4.93 \\
5.11 \\
5.26 \\
5.36 \\
5.45 \\
5.52 \\
5.62\end{array}$ & $\begin{array}{l}3.33 \\
3.59 \\
3.88 \\
4.10 \\
4.29 \\
4.45 \\
4.69 \\
4.87 \\
5.02 \\
5.13 \\
5.23 \\
5.38\end{array}$ & $\begin{array}{l}2.71 \\
2.81 \\
2.93 \\
3.03 \\
3.11 \\
3.17 \\
3.27 \\
3.34 \\
3.39 \\
3.43 \\
3.46 \\
3.50\end{array}$ & $\begin{array}{l}2.47 \\
2.59 \\
2.70 \\
2.80 \\
2.88 \\
2.97 \\
3.09 \\
3.18 \\
3.26 \\
3.32 \\
3.36 \\
3.44\end{array}$ & $\begin{array}{l}2.64 \\
2.72 \\
2.82 \\
2.92 \\
3.01 \\
3.08 \\
3.18 \\
3.25 \\
3.30 \\
3.34 . \\
3.38 \\
3.42\end{array}$ & $\begin{array}{l}2.40 \\
2.50 \\
2.62 \\
2.73 \\
2.82 \\
2.91 \\
3.04 \\
3.13 \\
3.20 \\
3.24 \\
3.29 \\
3.35\end{array}$ & $\begin{array}{l}2.52 \\
2.62 \\
2.74 \\
2.84 \\
2.91 \\
2.99 \\
3.11 \\
3.20 \\
3.27 \\
3.32 \\
3.36 \\
3.42\end{array}$ & $\begin{array}{l}2.53 \\
2.63 \\
2.76 \\
2.85 \\
2.92 \\
3.00 \\
3.12 \\
3.21 \\
3.28 \\
3.33 \\
3.37 \\
3.43\end{array}$ \\
\hline \multicolumn{10}{|c|}{ Chtcopee Shale } \\
\hline $\begin{array}{l}50 \\
100 \\
150 \\
200 \\
250 \\
300 \\
400 \\
500 \\
600 \\
700 \\
800 \\
1000\end{array}$ & $\begin{array}{l}5.40 \\
5.44 \\
5.48 \\
5.50 \\
5.53 \\
5.55 \\
5.58 \\
5.62 \\
5.64 \\
5.65 \\
5.67 \\
5.67\end{array}$ & $\begin{array}{l}5.07 \\
5.13 \\
5.17 \\
5.20 \\
5.23 \\
5.26 \\
5.30 \\
5.34 \\
5.36 \\
5.40 \\
5.41 \\
5.45\end{array}$ & $\begin{array}{l}4.80 \\
4.85 \\
4.90 \\
4.95 \\
4.99 \\
5.03 \\
5.10 \\
5.16 \\
5.22 \\
5.25 \\
5.29 \\
5.35\end{array}$ & $\begin{array}{l}3.21 \\
3.22 \\
3.22 \\
3.23 \\
3.24 \\
3.24 \\
3.26 \\
3.26 \\
3.27 \\
3.28 \\
3.28 \\
3.30\end{array}$ & $\begin{array}{l}3.13 \\
3.15 \\
3.16 \\
3.18 \\
3.19 \\
3.20 \\
3.21 \\
3.22 \\
3.23 \\
3.24 \\
3.25 \\
3.27\end{array}$ & $\begin{array}{l}3.07 \\
3.09 \\
3.11 \\
3.12 \\
3.13 \\
3.14 \\
3.15 \\
3.16 \\
3.17 \\
3.18 \\
3.19 \\
3.19\end{array}$ & $\begin{array}{l}2.91 \\
2.95 \\
2.97 \\
2.99 \\
3.00 \\
3.02 \\
3.04 \\
3.06 \\
3.07 \\
3.08 \\
3.09 \\
3.11\end{array}$ & $\begin{array}{l}3.03 \\
3.05 \\
3.06 \\
3.07 \\
3.07 \\
3.08 \\
3.10 \\
3.10 \\
3.11 \\
3.13 \\
3.13 \\
3.14\end{array}$ & $\begin{array}{l}3.04 \\
3.06 \\
3.06 \\
3.07 \\
3.07 \\
3.09 \\
3.10 \\
3.10 \\
3.11 \\
3.13 .13 \\
3.13 \\
3.15\end{array}$ \\
\hline \multicolumn{10}{|c|}{ Berea_Sandscone } \\
\hline $\begin{array}{r}50 . \\
100 . \\
150 . \\
200 \\
250 \\
300 . \\
400 . \\
500 . \\
600 . \\
700 . \\
800 \\
1000\end{array}$ & $\begin{array}{l}3.46 \\
3.60 \\
3.70 \\
3.77 \\
3.83 \\
3.87 \\
3.94 \\
3.99 \\
4.02 \\
4.05 \\
4.08 \\
4.11\end{array}$ & $\begin{array}{l}3.39 \\
3.56 \\
3.69 \\
3.75 \\
3.80 \\
3.84 \\
3.90 \\
3.95 \\
3.97 \\
4.00 \\
4.02 \\
4.05\end{array}$ & $\begin{array}{l}3.14 \\
3.33 \\
3.49 \\
3.61 \\
3.68 \\
3.74 \\
3.83 \\
3.89 \\
3.93 \\
3.97 \\
3.99 \\
4.02\end{array}$ & $\begin{array}{l}2.30 \\
2.39 \\
2.47 \\
2.52 \\
2.56 \\
2.59 \\
2.64 \\
2.67 \\
2.69 \\
2.71 \\
2.72 \\
2.74\end{array}$ & $\begin{array}{l}2.28 \\
2.36 \\
2.44 \\
2.49 \\
2.53 \\
2.56 \\
2.61 \\
2.64 \\
2.66 \\
2.68 \\
2.69 \\
2.71\end{array}$ & $\begin{array}{l}2.27 \\
2.38 \\
2.46 \\
2.51 \\
2.55 \\
2.57 \\
2.61 \\
2.64 \\
2.67 \\
2.69 \\
2.71 \\
2.73\end{array}$ & $\begin{array}{l}2.18 \\
2.29 \\
2.37 \\
2.42 \\
2.46 \\
2.49 \\
2.53 \\
2.55 \\
2.57 \\
2.59 \\
2.60 \\
2.63\end{array}$ & $\begin{array}{l}2.24 \\
2.34 \\
2.42 \\
2.48 \\
2.52 \\
2.55 \\
2.60 \\
2.63 \\
2.66 \\
2.67 \\
2.69 \\
2.70\end{array}$ & $\begin{array}{l}2.24 \\
2.34 \\
2.42 \\
2.48 \\
2.52 \\
2.56 \\
2.60 \\
2.64 \\
2.66 \\
2.68 \\
2.69 \\
2.70\end{array}$ \\
\hline
\end{tabular}

Table 1.

Table 1. P-, SH-, and SV-wave velocities measured in this experiment. 


\begin{tabular}{|l|c|c|c|}
\hline & $\begin{array}{l}\text { Chelmsford } \\
\text { Granite }\end{array}$ & $\begin{array}{l}\text { Chicopee } \\
\text { Shale }\end{array}$ & $\begin{array}{l}\text { Berea } \\
\text { Sandstone }\end{array}$ \\
\hline $\begin{array}{l}\text { preferred orientation } \\
\text { of pores/cracks }\end{array}$ & $* * *$ & $*$ \\
\hline bedding or foliation & $*$ & $* *$ & $* *$ \\
\hline constituent minerais & $*$ & $*$ & $*$ \\
\hline
\end{tabular}

Table 2. Factors contributing to velocity anisotropy of three rocks studied in this experiment. The number of stars indicates relative importance of that factor in causing velocity anisotropy in that rock. 
APPENDIX A: ESTIMATE OF ERRORS

Arrival time measurement

\begin{tabular}{|c|c|c|}
\hline $\mathrm{P}$ wave & $\begin{array}{l} \pm 0.012 \mathrm{msec}(\leq 200 \text { bars }) \\
\pm 0.006 \mathrm{msec}(>200 \text { bars })\end{array}$ & $\begin{array}{l} \pm 0.06 \% \quad(\leq 200 \text { bars }) \\
\pm 0.03 \% \quad(>200 \text { bars })\end{array}$ \\
\hline S wave & $\begin{array}{l} \pm 0.024 \mathrm{msec}(\leq 200 \text { bars }) \\
\pm 0.015 \mathrm{msec}(>200 \text { bars })\end{array}$ & $\begin{array}{l} \pm 0.08 \% \quad(\leq 200 \text { bars }) \\
\pm 0.05 \% \quad(>200 \text { bars })\end{array}$ \\
\hline Length measurement & \pm 0.0005 in & $\pm 0.025 \%$ \\
\hline Weight measurement & $\pm 0.025 \mathrm{~g}$ & $\pm 0.004 \%$ \\
\hline $\mathrm{V}_{\mathrm{P}}$ & $\begin{array}{l} \pm 0.010 \mathrm{~km} / \mathrm{sec}(\leq 200 \text { bars }) \\
\pm 0.005 \mathrm{~km} / \mathrm{sec}(>200 \text { bars })\end{array}$ & $\begin{array}{l} \pm 0.24 \%(\leq 200 \text { bars }) \\
\pm 0.15 \% \quad(>200 \text { bars })\end{array}$ \\
\hline $\mathrm{V}_{\mathrm{S}}$ & $\begin{array}{l} \pm 0.008 \mathrm{~km} / \mathrm{sec}(\leq 200 \text { bars }) \\
\pm 0.004 \mathrm{~km} / \mathrm{sec}(>200 \text { bars })\end{array}$ & $\begin{array}{l} \pm 0.28 \% \quad(\leq 200 \text { bars }) \\
\pm 0.15 \% \quad(>200 \text { bars })\end{array}$ \\
\hline$\rho$ & $\pm 0.0025 \mathrm{~g} / \mathrm{cm}^{3}$ & $\pm 0.10 \%$ \\
\hline $\mathrm{C}_{11}$ & \pm 2600 bars & $\pm 0.34 \%$ \\
\hline$c_{12}$ & \pm 4000 bars & $\pm 2.35 \%$ \\
\hline$c_{13}$ & \pm 25000 bars & $\pm 10 \%$ \\
\hline $\mathrm{C}_{33}$ & \pm 2600 bars & $\pm 0.42 \%$ \\
\hline$c_{44}$ & \pm 1400 bars & $\pm 0.54 \%$ \\
\hline$E_{\mathrm{V}}$ & \pm 54500 bars & $\pm 11 \%$ \\
\hline$E_{h}$ & \pm 81400 bars & $\pm 12 \%$ \\
\hline$v_{1}$ & \pm 0.020 & $\pm 17 \%$ \\
\hline$v_{2}$ & \pm 0.055 & $\pm 16 \%$ \\
\hline$v_{3}$ & \pm 0.029 & $\pm 11 \%$ \\
\hline $\mathrm{K}$ & \pm 65500 bars & $\pm 17 \%$ \\
\hline
\end{tabular}


